\title{
Molecular systematics and traditional medical microbiologists-problems and solutions
}

The detection and measurement of DNA sequence variation among bacteria is now routine, and techniques such as restriction enzyme length polymorphism analysis and direct sequencing are generating ever increasing amounts of data. This is having a major impact on the practice of bacterial systematics and molecular epidemiology. Many medical microbiologists are uncertain about how they should react to these developments, and some feel that they raise broader questions about relationships with systematists in general. ${ }^{1}$ The resistance of a small cohort of die-hard traditionalists to new technologies is easy to understand in the light of Planck's principle of resistance to innovation: "a scientific truth does not triumph by convincing its opponents and making them see the light, but rather because its opponents eventually die, and a new generation grows up that is familiar with it." Nevertheless, many are right when they point out that the new molecular techniques fit uneasily into the diagnostic laboratory because they are commonly-but not universally-more complex, more expensive, and slower than traditional identification and typing methods; and they are right to look for guidance in the interpretation of tests which they have not developed or do not conduct themselves.

How should medical microbiologists proceed? Before trying to answer this question there is merit in considering the implications of the observation that systematists do not decide how to use new characters in isolation but in the light of their views on the nature of the taxonomic groups that they study. In the remarks that follow we concentrate on the species, traditionally the most important taxonomic category in biology. However, our overall conclusion-that considerable uncertainty and a sizeable judgemental element surrounds and enters into operational definitions - applies with equal force to other categories, whether subspecific, e.g., the clone, or supraspecific.

In his magisterial history of biology, Ernst $\mathrm{Mayr}^{3}$ has pointed out that although the entity designated "species" seems at first sight to be obvious, simple, and easily defined, it is not so, and "there is probably no other concept in biology that has remained so consistently controversial." A common way of resolving this problem has been to ignore it or evade it. Thus Porphyry ${ }^{4}$ in his "Isagoge", a commentary on Aristotle's predicables - terms like genus, property and difference - written in the 3rd Century AD says "...I shall put aside the investigation of certain profound questions concerning genera and species since such an undertaking requires more detailed examination ", and Charles Darwin in the Origin of Species restricted discussion of the species concept to a handful of sentences. These are scattered through the book, and one serves as a summary of them all: "In determining whether a form should be ranked as a species or a variety, the opinion of naturalists having sound judgement and wide experience seems the only guide to follow." Darwin hoped that when his views on evolution were generally admitted "systematists will be able to pursue their labours ... but they will not be incessantly haunted by the shadowy doubt whether this or that form be in essence a species. The endless disputes whether or not some 50 species of British brambles are true species will cease." He could not have been more mistaken; the debate still rages vigorously.

For the last 50 years discussions about species definitions have been dominated by the biological species concept of Mayr ${ }^{6}$ and others. He defines species as "groups of actually or potentially interbreeding natural populations, which are reproductively isolated from other such groups." This concept is, of course, only applicable to sexually reproducing organisms. It has had a markedly inhibitory effect on discussions about the nature of the bacterial species, and because of its influence some have been led to the reductio ad absurdum of concluding that it does not exist. ${ }^{7}$ Maynard Smith has commented provocatively that "In bacteria, it seems that the evolving unit, between whose members genetic exchange is possible, is somewhat wider than the named "species", such as $S$. pneumoniae or N. meningitidis. Admittedly, my microbiological colleagues feel that the named entities do correspond to real groupings, but I suspect that this may mean that they would only know whether they had meningitis or the clap." 8

In spite of the powerful influence it has exerted on debate, the biological species concept has engendered a number of compelling objections from systematists. Two are particularly pertinent for prokaryotes. Templeton ${ }^{9}$ has referred to the major problem that large portions of the organic world-including many eukaryotes - reproduce asexually and are thus outside its logical domain, despite powerful arguments necessitating the inclusion of such organisms under the umbrella of some kind of species concept. An interesting paradox here is the demonstration ${ }^{10}$ that asexual rotifers, which always reproduce parthogenetically, not only form species but have taxa which 
actually are more consistently recognised than those from the sexual species. Not for nothing has Maynard Smith $^{11}$ described these organisms as an evolutionary scandal! The other major objection to the biological species concept is that it is unworkable in practice, even with organisms to which it could be, in theory, applied. ${ }^{12}$ In other words, it does not translate well to an operational definition. Thus in practice most systematists eschew reproductive isolation as a criterion because of the practical difficulty of testing for gene flow and the impossibility of testing for it in museum specimens and extinct species. Inferences are made instead from differences revealed by the examination of morphological, biochemical, serological and cytogenetic features.

Microbiologists are full members of the taxonomic main stream in this regard. Through an evolutionary process, with pragmatism as a guide, they have developed operational rules for delimiting bacterial species. Thus, Staley and Krieg ${ }^{13}$ in Bergey's Manual define a bacterial species as "a collection of strains that share many features in common and differ considerably from other strains" and state that "a species consists of the type strain and all other strains that are considered to be sufficiently similar to it as to warrant inclusion with it in the species." This Darwinian attitude is summarised in their comment that "this concept of a species obviously involves making subjective judgement." In numerical taxonomy studies analysing physiological, biochemical and morphological characters, an $80 \%$ similarity between strains has been found to approximate towards a definition of species level. Sneath" remarks, however, that "good scientific judgement in the light of other knowledge is indispensable for interpreting the results of numerical taxonomy." Johnson ${ }^{15}$ has provided a guide for DNA homology studies; this also emphasises the judgemental nature of decisions about setting exact levels of homology above which organisms are considered to be members of the same species. An ad hoc committee of the International Committee for Systematic Bacteriology ${ }^{16}$ has concluded that DNA re-association provides the best applicable procedure for the operational definition of a species and recommends that "the phylogenetic definition of a species generally would include strains with approximately $70 \%$ or greater DNA-DNA relatedness and with $5^{\circ} \mathrm{C}$ or less $\Delta \mathrm{Tm}$. Both values must be considered." DNA sequence data-whether direct or obtained by methods such as restriction fragment analysis - usually lends itself to quantitative analysis, and it is easy to see how these rules can be applied to it.

These principles are all very well for the systematist, with intuitive skills honed by long apprenticeship to other systematists. Nevertheless even they disagree, often along the lines of "lumpers" and "splitters" as described by Kant: "those who are more especially speculative are...hostile to heterogeneity, and are always on the watch for the unity of the genus; those on the other hand, who are more especially empirical, are constantly endeavoring to differentiate nature in such manifold fashion as almost to extinguish the hope of ever being able to determine its appearances in accordance with universal principles." 17 How, therefore, are medical microbiologists-who look to systematists as providers of answers rather than sources of difficulties - to judge for themselves that groupings are natural? A simple but powerful philosophical principle - the consilience of inductions - provides the way forward. First enunciated by William Whewell more than 150 years ago, ${ }^{18}$ it states that " the maxim by which all systems professing to be natural must be tested is this:- that the arrangement obtained from one set of characters coincides with the arrangement $o b$ tained from another set." ${ }^{19}$ Its use removes the need to worry about the lack of clear operational definitions of taxonomic entities, and it can be applied at any taxonomic level and to any type of character, being as useful for the characterisation of subspecific typing schemes as in the delineation of species. Thus our confidence in a classification scheme for a particular organism is much increased if the groupings arrived at by completely different methods-e.g., serological and restriction fragment length polymorphism analysis -are identical or very close. If they are not, they signal, at least, caution in interpretation, the need for further development of the tests, and, almost certainly, interesting questions for resolution by students of variation in natural bacterial populations. The clear benefits that come from comparative studies on different methods for identification and typing are exemplified by work on Salmonella, ${ }^{20}$ in which comparison of serotype with multilocus enzyme electropherotype gave groupings which generally coincided, reinforcing the view that the former method usually marks genetically related strains, and explaining why it is epidemiologically useful. That the concordance was not complete points to deficiencies in serotyping, particularly in resolving power.

Searches for consilience do not always find it. This is not too surprising, given that organisms know no philosophy. Nevertheless, such studies often give results of considerable practical importance. We quote from the final paragraph of a study in which traditional and molecular methods for staphylococcal typing were compared $^{21}$ - one that shows the benefits of the pragmatic, comparative approach: "No typing method clearly prevailed... and ultimately a combination of two methods may be the most efficacious ... the choice depends upon the resources available to the laboratory and the level of expertise..." Darwin's principles of "judgement and sound experience" are clearly still in operation!

The development and application of methods for measuring DNA sequence variation is having as great a revolutionary impact on systematics as the publication of The Origin of Species. As custodians of traditional methods and controllers of much of the raw material, medical microbiologists are in a key position to direct these events to their advantage by 
initiating, facilitating and participating in joint studies with molecular systematists. When a revolution is unstoppable, better to be on the winning side!

\section{References}

1. Magee JT. Forsaking the tome-a worms' eye view of taxonomy. J Med Microbiol 1993; 39: 401-402.

2. Planck M. Scientific autobiography. Trans Gaynor F. London, Williams and Norgate. 1950:33, 34

3. Mayr E. The growth of biological thought. Cambridge, MA, The Belknap Press. 1982.

4. Porphyry the Phoenician. Isagoge. Trans Warren EW. Ontario, Pontifical Institute of Mediaeval Studies. 1975.

5. Darwin $C$. The origin of species by natural selection. London, Watts. 1929: 35.

6. Mayr E. Systematics and the origin of species. Cambridge, Cambridge University Press. 1942.

7. Cowan ST. The microbial species - a macromyth? In: Microbial classification. $12^{\text {th }}$ symposium of the Society for General Microbiology. Cambridge, Cambridge University Press. 1962.

8. Smith JM. The evolution of prokaryotes: does sex matter? Annu Rev Ecol Syst 1990; 21: 1-12.

9. Templeton AR. The meaning of species and speciation: a genetic perspective. In: Otte D, Endler JA (eds) Speciation and its consequences. Sunderland, MA, Sinauer Associates. 1989.

10. Holman EW. Recognizability of sexual and asexual species of rotifers. System Zool 1987; 36: 381-386.

11. Smith JM. Contemplating life without sex. Nature 1986; 324 : $300-301$.
T. H. Pennington

Department of Medical Microbiology, University of Aberdeen, Foresterhill, Aberdeen AB9 2ZD
12. Cracraft J. Speciation and its ontology. In: Otte D, Endler JA (eds) Speciation and its consequences. Sunderland, MA. Sinauer Associates. 1989.

13. Staley JT, Krieg NR. Classification of prokaryote organisms: an overview. In: Krieg NR, Holt JG (eds) Bergey's Manual of systematic bacteriology, vol. 1. Baltimore, Williams and Wilkins Co. 1984.

14. Sneath PHA. Numerical taxonomy. In: Krieg NR, Holt JG (eds) Bergey's Manual of systematic bacteriology, vol. 1. Baltimore, Williams and Wilkins Co. 1984.

15. Johnson JL. Nucleic acids in bacterial classifications. In: Krieg NR, Holt JG (eds) Bergey's Manual of systematic bacteriology, vol. 1. Baltimore, Williams and Wilkins Co. 1984.

16. Wayne LG, Brenner DJ, Colwell RR et al. Report of the ad hoc committee on reconciliation of approaches to bacterial systematics. Int J Syst Bacteriol 1987; 37: 463-464.

17. Kant, I. Kritik der reinen vernunft, 2 nd edn; trans Smith NK. Basingstoke, Macmillan. 1992: 540.

18. Fisch M, Schaffer S (eds). William Whewell. A composite portrait. Oxford, Clarendon Press. 1991.

19. Whewell W. The philosophy of the inductive sciences. London, Parker. 1840: 1 : 521.

20. Selander RK, Smith NH. Molecular population genetics of Salmonella. Rev Med Microbiol 1990; 1 : 219-228.

21. Tenover FC, Arbeit R, Archer G et al. Comparison of traditional and molecular methods of typing isolates of Staphylococcus aureus. J Clin Microbiol 1994; 32 : 407-415. 